\title{
Thrombosis due to Heparin-induced Thrombocytopenia in Cardiac Surgery: is Fondaparinux an Effective Treatment?
}

\author{
David Barilla $^{1 *}$, Gian Luca Martinelli ${ }^{2}$, Attilio Cotroneo ${ }^{2}$, Angelo Romano ${ }^{3}$ and Pasquale lacopino ${ }^{4}$ \\ ${ }^{1}$ Vascular Surgery Department, Ospedali Riuniti "Bianchi Melacrino Morelli", Reggio, Calabria, Italy \\ ${ }^{2}$ Cardiac Surgery Department, Clinica San Gaudenzio gruppo Policlinico di Monza, Novara, Italy \\ ${ }^{3}$ CardioVascular Anesthesiology Department, Clinica San Gaudenzio gruppo Policlinico di Monza, Novara, Italy \\ ${ }^{4}$ Haematology Unit, National Cancer Research Centre, Istituto Tumori "Giovanni Paolo II", Bari, Italy
}

"Corresponding author: David Barilla, Vascular Surgery Department, Ospedali Riuniti "Bianchi Melacrino Morelli", Reggio, Calabria, Italy, Tel: +393284550063; E-mail: davidbarilla.db@gmail.com

Rec date: March 10, 2015; Acc date: March 29, 2016; Pub date: March 31, 2016

Copyright: (c) 2016 Barilla D, et al. This is an open-access article distributed under the terms of the Creative Commons Attribution License, which permits unrestricted use, distribution, and reproduction in any medium, provided the original author and source are credited.

\begin{abstract}
Objective: To determine whether fondaparinux is effective in the treatment of thrombosis due to heparin-induced thrombocytopenia (HIT) in cardiac surgery we reported three cases successfully treated with fondaparinux and withdrawal of all heparins.

Patients: All three patients were female and underwent heart valve replacement using cardiopulmonary bypass. Combined clinical criteria, "4T score" (Thrombocytopenia, Timing, Thrombosis, and absence of oTher explanations) and laboratory testing have been used for diagnosis. In all patients the point of heparin immunization occurred in the preoperative period, during the angiography when a standard dose of UFH (5,000 IU) was administered. Then, during cardiac surgery, patients received a high dose of UFH, and later LMWH was used. Thrombocytopenia occurring between postoperative days 5 and 10 was associated with severe venous end/or arterial thrombosis. Other causes of thrombocytopenia were excluded. Thus, there was a high clinical suspicion (4T's=7 points) of HIT, and while awaiting the results of laboratory tests all sources of heparin were removed and fondaparinux was administered at therapeutical doses. Clinical and cardio-pulmonary thrombosis imaging resolution and platelet recovery were achieved in all cases with no new thrombotic or haemorrhagic event.
\end{abstract}

Conclusions: Despite significant limitations exist regarding this retrospective evaluation, our data further support the observational evidence that fondaparinux is a safe and effective option in HIT-related thromboembolic complications with a good anticoagulant action and low risk of bleeding events.

Keywords HITT; Cardiac surgery; Heparin; Thrombosis; Fondaparinox

\section{Introduction}

Thrombocytopenia after cardiac surgery may result from HIT, therefore it is included in differential diagnosis in all the patients with unexplained fall of platelet count.

HIT is defined as a fall of platelet count of about $50 \%$ occurring within 5 to 14 days after the start of heparin therapy that induces an intense prothrombotic state, due to an immune reaction against platelet factor 4 (PF4)-heparin complexes (Type $2 \mathrm{HIT}$ ), and resolves after stopping heparin $[1,2]$. Type 1 HIT is a mild thrombocytopenia that usually develops within 48 hours of initiating heparin. Only if the platelet count continues to fall in a non-bleeding patient, type 2 HIT should be considered and all heparins should be stopped [3]. HIT antibodies (H-IgG) occur more often in postsurgical than medical patients, and in those treated with unfractionated heparin (UFH) rather than low molecular weight heparin (LMWH) [3,4]. Overall, the absolute post-operative risk for HIT is higher with UFH (2\% to $3 \%$ ), compared to (LMWH) (0.2\% to 0.6) [2,5-7]. One hypothesis to explain why cardiosurgical patients have the highest prevalence of $\mathrm{PF} 4 / \mathrm{H}-\mathrm{IgG}$ is that extensive tissue injury causes widespread platelet activation releasing large quantity of PF4 that combines with heparin [8]. Furthermore, HIT is more likely to occur using high doses of UFH, although very small doses may also result in thrombocytopenia.

HIT can be seen with isolated thrombocytopenia (HIT) or concurrently with thrombotic complications (HITT). Combined clinical criteria and laboratory testing, are currently recommended for HIT diagnosis [9], but it remains a difficult condition to diagnose [10]. It is important to underline, in this regard, that many patients suspected of having HIT are finally proven to have different thrombotic disorders [11].

If HIT is suspected because of intermediate or high "4T score" (Thrombocytopenia, Timing, Thrombosis, and absence of oTher explanations) (Table 1) [5], all heparin products must be discontinued and non-heparin anticoagulant initiated. In the meantime, laboratory testing should be carried out $[6,8,11,12]$.

Effective non-heparin anticoagulants include the FDA-approved direct thrombin inhibitors and the selective factor Xa inhibitors, such as fondaparinux $[6,13]$. Even if off-label for this condition, fondaparinux represents an attractive treatment for patients who develop HIT because it is not derived from heparin, has negligible to no cross-reactivity with HIT antibodies $[6,13,14]$, and is an effective treatment in both HIT and non-HIT settings of thrombosis. 
Citation: Barilla D, Martinelli GL, Cotroneo A, Romano A, lacopino P (2016) Thrombosis due to Heparin-induced Thrombocytopenia in Cardiac Surgery: is Fondaparinux an Effective Treatment?. J Cardiovasc Dis Diagn 4: 240. doi:10.4172/2329-9517.1000240

Page 2 of 5

\begin{tabular}{|c|c|c|c|}
\hline Category & 2 points & 1 point & 0 points \\
\hline $\begin{array}{l}1 . \\
\text { Thrombocyto } \\
\text { penia }\end{array}$ & $\begin{array}{l}\text { Platelet } \\
\text { count } \\
\text { fall }>50 \% \text { and } \\
\text { platelet nadir } \\
\geq 20 \times 109 \mathrm{~L} \\
-1\end{array}$ & $\begin{array}{l}\text { Platelet count fall } 30 \%- \\
50 \% \text { or platelet nadir } 10- \\
19 \times 109 \mathrm{~L}-1\end{array}$ & 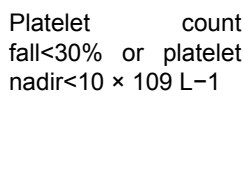 \\
\hline $\begin{array}{l}\text { 2. Timing of } \\
\text { platelet } \\
\text { count fall }\end{array}$ & $\begin{array}{l}\text { Clear onset } \\
\text { between } \\
\text { days } 5 \text { and } \\
10 \text { or platelet } \\
\text { fall } \leq 1 \text { day } \\
\text { (prior } \\
\text { heparin } \\
\text { exposure } \\
\text { within } 30 \\
\text { days) }\end{array}$ & $\begin{array}{l}\text { Consistent with days } 5- \\
10 \text { fall, but not clear (e.g. } \\
\text { missing platelet counts) } \\
\text { or onset after day } 10 \text { or } \\
\text { fall } \leq 1 \text { day (prior heparin } \\
\text { exposure } 30-100 \text { days } \\
\text { ago) }\end{array}$ & $\begin{array}{l}\text { Platelet count fall }<4 \\
\text { days without recent } \\
\text { heparin exposure }\end{array}$ \\
\hline $\begin{array}{l}3 . \\
\text { Thrombosis } \\
\text { or other } \\
\text { sequelae }\end{array}$ & $\begin{array}{l}\text { New } \\
\text { thrombosis } \\
\text { (confirmed) } \\
\text { or skin } \\
\text { necrosis at } \\
\text { heparin } \\
\text { injection } \\
\text { sites or } \\
\text { acute } \\
\text { systemic } \\
\text { reaction after } \\
\text { intravenous } \\
\text { heparin } \\
\text { bolus }\end{array}$ & $\begin{array}{l}\text { Progressive or recurrent } \\
\text { thrombosis or } \\
\text { nonnecrotizing } \\
\text { (erythematous) skin } \\
\text { lesions or suspected } \\
\text { thrombosis (not proven) }\end{array}$ & None \\
\hline $\begin{array}{l}\text { 4. Other } \\
\text { causes for } \\
\text { thrombocyto } \\
\text { penia }\end{array}$ & $\begin{array}{l}\text { None } \\
\text { apparent }\end{array}$ & Possible & Definite \\
\hline
\end{tabular}

Total score of $\geq 6$ points, high probability of HIT; 4-5 points, intermediate probability of $\mathrm{HIT} ; \leq 3$ points, low probability of HIT. CPB, cardiopulmonary bypass [5]

Table 1: Estimating the pretest probability of HIT: the four Ts scoring system.

We reported three cases, among more than 4,000 cardiosurgical patients observed in the last 5 years, with HITT successfully treated with fondaparinux and withdrawal of all heparins.

\section{Case Report 1}

A 72-years old woman suffering from severe symptomatic aortic stenosis with no co-morbidities underwent aortic valve replacement (AVR) through ministernotomy. Before surgery, coronary angiography was performed and 5,000 IU UFH was given. On admission, her platelet count was $210 \times 109 / \mathrm{L}$ Aortic cross clamp and cardiopulmonary bypass $(\mathrm{CPB})$ times were respectively 70 and 94 minutes. The patient experienced an uneventful recovery and anticoagulation therapy with nadroparin calcium was continued.

On day 8 , patient presented right inferior limb oedema suggestive of deep venous thrombosis (DVT). Duplex Ultra Sound (DUS) confirmed a common femoral vein thrombosis; therefore, Vitamin K Antagonist (VKA) therapy was started. The day after, extreme thrombocytopenia (platelet count $=27 \times 109 / \mathrm{L}$ ) was detected. Because of high probability of HITT ( $4 \mathrm{~T}^{\prime} \mathrm{s}=7$ points), VKA therapy was discontinued and LWMH was replaced with fondaparinux $5 \mathrm{mg}$ administered once daily, avoiding platelets transfusions. CT-scan revealed multiple thrombi occluding right pulmonary artery bifurcation and left subsegmentarian arteries. In addition, there was a venous thrombosis involving the superior cava at the azygous vein confluence as well as an inferior cava vein thrombosis extended for 5 $\mathrm{cm}$ above the iliac veins (Figure 1). Positive ELISA test for anti-heparin antibodies strengthened clinical suspicion of HITT.

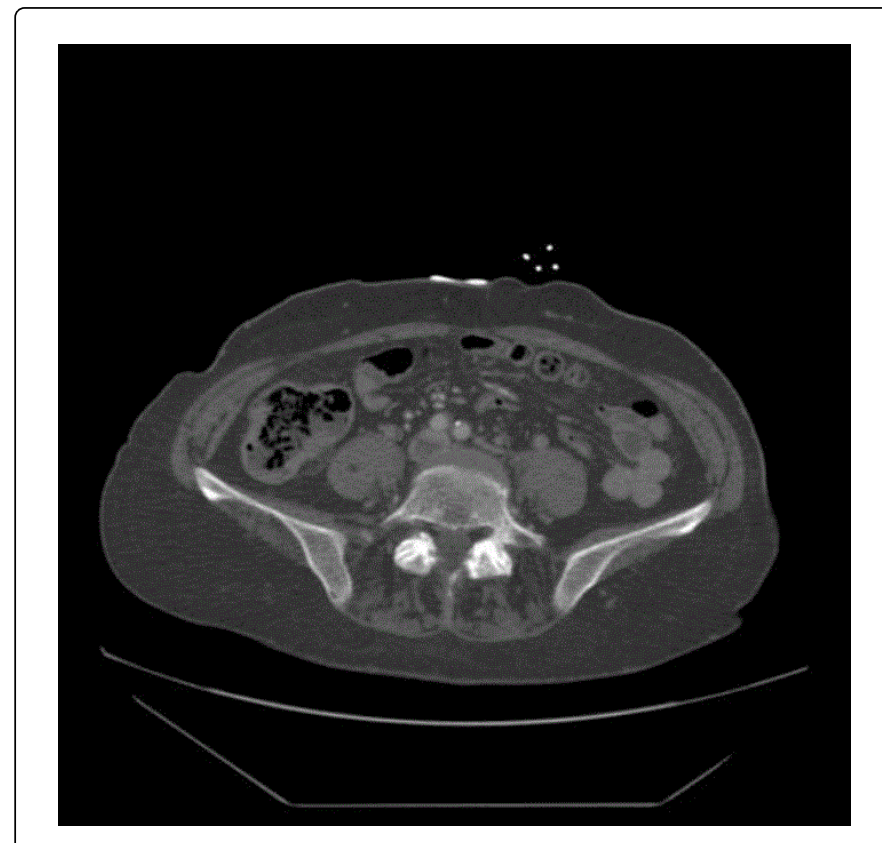

Figure 1: A CT scan revealed a venous thrombosis of the inferior cava vein extended for $5 \mathrm{~cm}$ above the iliac veins.

After switch to anticoagulation with fondaparinux, progressive increase of platelet count was observed. When platelet count was more than $100 \times 109 / \mathrm{L}$, VKA therapy was started along with fondaparinux for 5 days. Before discharge, we observed the regression of limb oedema and CT-scan revealed the resolution of pulmonary embolism. One month later, platelet count was $223 \times 109 / \mathrm{L}$.

\section{Case Report 2}

Our second patient was an 83-years old woman suffering from symptomatic aortic stenosis with initial left ventricular dysfunction with moderate increase of systolic pulmonary artery pressure, and multiple co-morbidities: hypertension, history of arrhythmia, and chronic obstructive pulmonary disease (COPD). During the coronary angiography, standard dose of UFH (5,000 IU) was injected. We performed AVR in ministernotomy. $\mathrm{CPB}$ and cross clamp times were 95 and 75 minutes. After six days, the patient was dyspnoeic and asthenic. CT-scan showed right atrial thrombosis and pulmonary embolism. Transoesaphageal echocardiography (TOE) suggested partial valve thrombosis (Figure 2). Platelet count was $40 \times 109 / \mathrm{L}$, associated with positive ELISA test for anti-heparin antibodies. Therefore, we suspended LWMH, and started fondaparinux $5 \mathrm{mg}$, administered once daily. After one week, platelet count reached $100 \times 109 / \mathrm{L}$ and (VKA) therapy was given - together fondaparinux for the first 5 days - over the next 6 months. On transthoracic echocardiography, the bioprosthesis leaflets were completely thrombus free with medium gradient $8 \mathrm{mmHg}$, and CT-scan showed the complete recovery of pulmonary embolism. At 2-years follow-up, this 
Citation: Barilla D, Martinelli GL, Cotroneo A, Romano A, lacopino P (2016) Thrombosis due to Heparin-induced Thrombocytopenia in Cardiac Surgery: is Fondaparinux an Effective Treatment?. J Cardiovasc Dis Diagn 4: 240. doi:10.4172/2329-9517.1000240

Page 3 of 5

patient is under monotherapy with acetylsalicylic acid (ASA) $100 \mathrm{mg}$ daily, and currently is in NYHA class II.

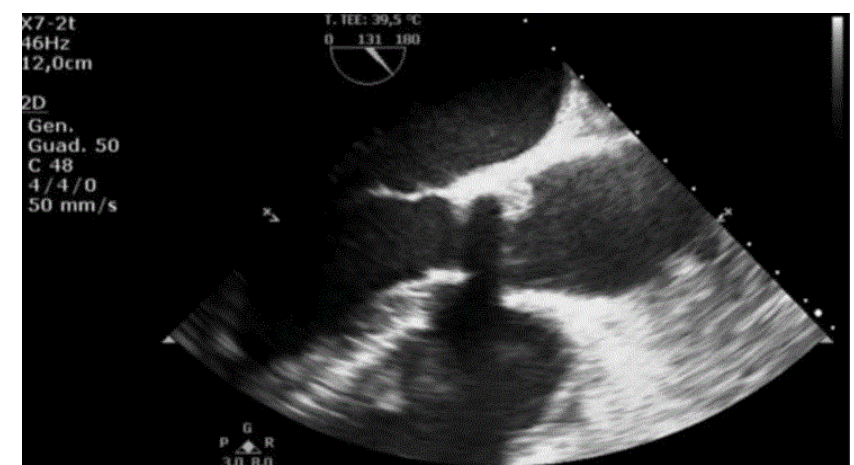

Figure 2: Transoesaphageal echocardiography (TOE) shows partial valve thrombosis with a fix right cusp.

\section{Case Report 3}

The third case was a 70-years old female who underwent mitralaortic replacement with a bioprosthesis. During angiography, she received 5,000 IU UFH. In post-operative day 3, during LWMH prophylactic treatment, she showed symptoms of transient ischemic attack (TIA), and therefore anticoagulant shift from LWMH to VKA was done. She was in sinus rhythm. Two days later, the patient had a stroke with partial hemiparesis. Cerebral CT scan confirmed the presence of recent ischemic lesion. In addition, TOE showed the presence of left atrial thrombus. At the same time, a dramatic decline of platelet count was observed, reaching $7 \times 109 / \mathrm{L}$ two days later (4T's=7 points). Consequently, we stopped LWMH and started anticoagulant therapy with fondaparinux $5 \mathrm{mg} /$ once daily, avoiding platelet transfusions. Subsequently, positive ELISA test for anti-heparin antibodies supported the clinical suspicion of HITT. We saw a gradual increase in platelet count, and started VKA therapy when platelet count improved to $100 \times 109 / \mathrm{L}$. Overall, fondaparinux was administered for 10 days (including an overlap of 5 days of VKA therapy) without any side effects. Gradually we noted the patient recovery from the stroke with a residual slight hyposthenia. TOE showed the complete resolution of thrombosis. At 5-years follow-up, she was in good condition on ASA therapy.

\section{Discussion}

In cardiac surgery, UFH is largely used at very high doses to guarantee adequate anticoagulation during CPB mainly for its short half-life and the availability of protamine sulfate to reverse its effects [15]. After surgery, either UFH or LMWH are used. This wide use of UFH together with extensive tissue injury justifies the reported high risk of developing HIT (2-3\%) in cardiac surgery patients [5]. Previously, a pooled analysis demonstrated that HIT incidence was $1.1 \%$ with porcine-intestine-derived UFH and $2.9 \%$ with bovine-lungderived UFH [16], but just one of our patients received bovine, the other two porcine UFH.

One striking finding of our case series was that the point of heparin immunization occurred in the preoperative period, during the angiography when standard dose of UFH (5,000 IU) was administered.
Notably, Foo et al. [17] reported positive test for anti-PF4/heparin antibodies in $10.1 \%$ of patients after cardiac catheterization.

Severe venous or arterial thrombosis in a patient on prophylactic or therapeutic doses of heparin combined with marked thrombocytopenia is the hallmark of HITT [18]. While thrombocytopenia is described in more than $20 \%$ of patients who underwent cardiac surgery, a typical clinical picture of HIT is observed only in $1-3 \%$, with a $20-30 \%$ mortality rate $[5,6,8,17]$. Particularly, whereas fall in platelet count, which occurs in the first four postoperative days, is unlikely due to HIT, thrombocytopenia occurring between postoperative days 5 and 10 is highly predictive of HIT [19]. In our cases, platelet counts declined dramatically 5 to 10 days after the start of UFH (typical-onset HIT) [6]. Severe thrombosis, complicated by acute pulmonary thromboembolism or stroke, was documented in all our cases between days 5 and 8 post-CPB. This is no surprise since the risk for thrombosis correlates with the extent of decrease of platelets, with a greater fall in platelet counts associated with a high risk of thrombosis [19].

Other causes of thrombocytopenia were excluded in all cases. Thus, there was a high clinical suspicion ( $4 \mathrm{~T}^{\prime} \mathrm{s}=7$ points) of $\mathrm{HIT}$, and while awaiting the results of laboratory tests all sources of heparin were removed. Anticoagulation with VKA was also discontinued as it can produce early hypercoagulability through depletion of protein C. VKA was immediately replaced with the non-heparin anticoagulant fondaparinux, avoiding platelets transfusions because they may further exacerbate the hypercoagulable state. Although there are a number of alternative anticoagulants that are recommended for a patient with HIT [18], our local approach to choice fondaparinux for patients who have normal renal function is based upon its subcutaneous administration, the no need for coagulation monitoring in routine practice, and the very low risk of major bleeding complications. As none of our cases had renal impairment or exacerbation of HITT manifestations during fondaparinux use [20], at therapeutical dose (5 $\mathrm{mg}$, once daily), the drug was given until after platelet counts were higher than $100 \times 109 / \mathrm{L}$. After this substantial platelet recovery VKA therapy was reintroduced (along with fondaparinux for 5 days and when INR was therapeutic) and we adopted the same approach, as suggested by a previous study [21] and current recommendations $[6,11,13]$.

Our clinical suspicion was subsequently strengthened by a positive ELISA test for anti-heparin antibodies, even if immunoassays can be positive in patients without clinical HIT (90\% sensitivity, 30-70\% specificity) $[9,12,22]$ because they fail to discriminate platelet activating from nonpathogenic antibodies [9]. Unfortunately, the more specific functional tests were unfeasible for our laboratory as for most clinical laboratories [22]. However, the detection of anti-heparin antibodies in patients with $4 \mathrm{~T}^{\prime} \mathrm{s}>6$ points have a posttest probability of HIT approaching 100\% [9]. In addition, following our decisionmaking about anticoagulant therapy, the progressive rise of platelet count was noted in all the patients, and it was one of our clinical parameters for clear diagnosis of HITT.

Fondaparinux is an available and practice off-label therapy with a good anticoagulant action and a low haemorrhagic rate $[6,14,21]$. Like LMWH, it can be administered once or twice daily. However, experience with fondaparinux use for HIT is based on case series or retrospective studies [6,21,23], therefore this drug is suggested as a therapeutical option with a low recommendation level [18]. In addition, concern was expressed about the possibility of new 
thrombotic events [11] as well as the occurrence of fondaparinuxinduced thrombocytopenia [24].

Our series underscored safety and efficacy of fondaparinux in cardiosurgical patients with severe HIT complicated by thrombosis. Indeed, cardio-pulmonary thrombosis imaging resolution and platelet recovery were achieved in all cases. None developed new thromboses. In addition, even if post-cardiac surgery patients have an increased risk of bleeding due to both surgical and non-surgical causes, our approach seems to be a safe strategy because no patient exhibited clinically significant hemorrhage complications.

Our results should be seen in the context of the limited existing therapy options for HITT [20]. Other alternative drugs have been used in HIT, which have different characteristics that make them suitable in different situations [6,25]: the heparinoid with anti-factor Xa activity danaparoid (Orgaran) and the direct thrombin inhibitors, lepirudin, argatroban and bivalirudin. Unfortunately, given the absence of data from randomized trials, most recommendations for their use in HITT are supported by low-grade evidence, analogously to what happens for fondaparinux $[18,20]$. In addition, all of these alternative anticoagulants carry a significant risk of bleeding complications, are not available in all institutions (i.e. lepirudin and danaparoid are no longer available in the US) and/or require monitoring of anticoagulation. Despite their utility in HIT remains undefined because it is supported only by few clinical reports, other emerging attractive therapies are the new oral anticoagulants (rivaroxaban, dabigatran, and apixaban), which are approved for thromboprophylaxis as well thromboembolic conditions. They do not interact with anti-PF4/heparin antibodies and have rapid onset of action [26], although, for example, dabigatran can increase INR and, therefore, INR measurements should be interpreted cautiously when this drug is switched to VKA. Finally, plasmapheresis can be used as salvage therapy to reduce antibody burden in patients with refractory or progressive thromboses on alternative anticoagulation [27].

In conclusion, our data further support the observational evidence that fondaparinux is a safe and effective option in HIT-related thromboembolic complications. Different types of alternative anticoagulants can be useful in different clinical scenarios but it is more important to suspect HIT when there are suggestive clinical factors, because prompt therapeutic decisions are vital for prognosis and outcomes. Despite its off-label use, the lack of indication supported by prospective studies and the obvious limitations of our study, fondaparinux appears to us effective, low cost, practical and available therapy with a good anticoagulant action and low risk of bleeding events.

\section{References}

1. Arepally GM, Ortel TL (2006) Clinical practice. Heparin-induced thrombocytopenia. N Engl J Med 355: 809-817.

2. Martel N, Lee J, Wells PS (2005) Risk for heparin-induced thrombocytopenia with unfractionated and low-molecular-weight heparin thromboprophylaxis: a meta-analysis. Blood 106: 2710-2715.

3. Gruel Y, Pouplard C (2010) Post-operative platelet count profile: the most reliable tool for identifying patients with true heparin-induced thrombocypenia after cardiac surgery. Journal of Thrombosis and Haemostasis 8: 27-29.

4. Amiral J, Marfaing-Koka A, Poncz M, Meyer D (1998) The biological basis of immune heparin-induced thrombocytopenia. Platelets 9: 77-91.

5. Warkentin TE, Greinacher A (2003) Heparin-induced thrombocytopenia and cardiac surgery. Ann Thorac Surg 76: 638-648.
6. Warkentin TE (2015) Heparin-induced thrombocytopenia in critically ill patients. Semin Thromb Hemost 41: 49-60.

7. Junqueira DRG, Perini E, Penholati RRM (2012) Unfractionated heparin versus low molecular weight heparin for avoiding heparin-induced thrombocytopenia in postoperative patients. Cochrane Database Syst Rev 9: CD007557.

8. Yoon JH, Jang IK (2011) Heparin-induced thrombocytopenia in cardiovascular patients: pathophysiology, diagnosis, and treatment. Cardiol Rev 19: 143-153.

9. Lee GM, Arepally GM (2013) Heparin-induced thrombocytopenia. Hematology Am Soc Hematol Educ Program 2013: 668-674.

10. Demma LJ, Levy JH (2011) Diagnosing heparin-induced thrombocytopenia in cardiac surgical patients: not as easy as you think. Anesth Analg 112: 747-749.

11. Warkentin TE (2011) How I diagnose and manage HIT. Hematology Am Soc Hematol Educ Program 2011: 143-149.

12. Lo GK, Juhl D, Warkentin TE, Sigouin CS, Eichler P, et al. (2006) Evaluation of pretest clinical score (4 T's) for the diagnosis of heparininduced thrombocytopenia in two clinical settings. J Thromb Haemost 4: 759-765.

13. Warkentin TE, Greinacher A, Koster A, Lincoff AM; American College of Chest Physicians (2008) Treatment and prevention of heparin-induced thrombocytopenia: American College of Chest Physicians EvidenceBased Clinical Practice Guidelines (8th Edition). Chest 133: 340S-380S.

14. Schindewolf M, Steindl J, Beyer-Westendorf J, Schellong S, Dohmen PM, et al. (2014) Frequent off-label use of fondaparinux in patients with suspected acute heparin-induced thrombocytopenia (HIT)-findings from the GerHIT multi-centre registry study. Thrombosis research 134: 29-35.

15. Ranucci $M$ (2015) Hemostatic and thrombotic issues in cardiac surgery. Semin Thromb Hemost 41: 84-90.

16. Schmitt BP, Adelman B (1993) Heparin-associated thrombocytopenia: a critical review and pooled analysis. Am J Med Sci 305: 208-215.

17. Foo SY, Everett BM, Yeh RW, Criss D, Laposata M, et al. (2006) Prevalence of heparin-induced thrombocytopenia in patients undergoing cardiac catheterization. Am Heart J 152: 290-291.

18. Linkins LA, Dans AL, Moores LK, Bona R, Davidson BL, et al. (2012) Treatment and prevention of heparin-induced thrombocytopenia: antithrombotic therapy and prevention of thrombosis: American College of Chest Physicians evidence-based clinical practice guidelines. CHEST Journal 141: e495S-e530S.

19. Greinacher A, Farner B, Kroll H, Kohlmann T, Warkentin TE, et al. (2005) Clinical features of heparin-induced thrombocytopenia including risk factors for thrombosis. Thromb Haemost 94: 132-135.

20. Greinacher A (2015) Clinical Practice. Heparin-Induced Thrombocytopenia. N Engl J Med 373: 252-261.

21. Lobo B, Finch C, Howard A, Minhas S (2008) Fondaparinux for the treatment of patients with acute heparin-induced thrombocytopenia. Thromb Haemost 99: 208-214.

22. Cuker A, Rux AH, Hinds JL, Cruz MD, Yarovoi SV, et al. (2013) Novel diagnostic assays for heparin-induced thrombocytopenia. Blood 121: 3727-3732.

23. Kang M, Alahmadi M, Sawh S, Kovacs MJ, Lazo-Langner A (2015) Fondaparinux for the treatment of suspected heparin-induced thrombocytopenia: a propensity score-matched study. Blood 125: 924-929.

24. Bhatt VR, Aryal MR, Shrestha R, Armitage JO (2013) Fondaparinuxassociated heparin-induced thrombocytopenia. Eur J Haematol 91: 437-441.

25. Wahba A (2011) Strategies in heparin-induced thrombocytopenia. Multimed Man Cardiothorac Surg 2011: mmcts.

26. Chaudhary RK, Khanal N, Giri S, Pathak R, Bhatt VR (2014) Emerging therapy options in heparin-induced thrombocytopenia. Cardiovasc Hematol Agents Med Chem 12: 50-58. 
Citation: Barilla D, Martinelli GL, Cotroneo A, Romano A, lacopino P (2016) Thrombosis due to Heparin-induced Thrombocytopenia in Cardiac Surgery: is Fondaparinux an Effective Treatment?. J Cardiovasc Dis Diagn 4: 240. doi:10.4172/2329-9517.1000240

Page 5 of 5

27. Jaben EA, Torloni AS, Pruthi RK, Winters JL (2011) Use of plasma exchange in patients with heparin-induced thrombocytopenia: a report of two cases and a review of the literature. J Clin Apher 26: 219-224. 